\title{
Processes structuring communities: evidence for trait-mediated indirect effects through induced polymorphisms
}

\author{
Peter T. Raimondi, Samantha E. Forde, Lynda F. Delph and Curtis M. Lively
}

\begin{abstract}
Raimondi, P. T., Forde, S. E., Delph, L. F. and Lively, C. M. 2000. Processes structuring communities: evidence for trait-mediated indirect effects through induced polymorphisms. - Oikos 91: 353-361.
\end{abstract}

\begin{abstract}
Trait-mediated indirect effects (TMIs) are changes in the density of one species that are caused by induced changes in one or more traits of an intervening species. For example, induced defense in a prey species may alter the nature of indirect effects that are mediated through that prey species. In the present study, we investigated the TMIs that stem from an interaction between a carnivorous whelk (Acanthina angelica) and an intertidal barnacle (Chthamalus anisopoma). Depending on the timing of the interaction, the predator either kills the barnacle or induces a predationresistant morph. Based on previous work that addressed the direct interactions between Chthamalus and other species in the community we predicted and subsequently found that community structure varies as a function of these differing effects. Specifically, we found that Acanthina has a positive indirect effect on mussels when it interacts with (kills) undefended adult barnacles. In contrast, the predator has a positive indirect effect on an encrusting algae (Ralfsia) when it comes into contact with juvenile barnacles, causing the induction of the predator-resistant morph. We suggest that further research should consider the role of environmentally induced polymorphisms in structuring communities.
\end{abstract}

P. T. Raimondi and S. E. Forde, Dept of Biology, Earth and Marine Sciences Building, Univ. of California, Santa Cruz, CA 95064, USA (raimondi@biology.ucsc.edu). - L.F. Delph and C. M. Lively, Dept of Biology, Indiana Univ., Bloomington, IN 47405-3700, USA.

Among the challenges facing ecologists is determining the importance of indirect effects in organizing communities. Two types of indirect effects may structure communities: density- and trait-mediated indirect effects (Abrams et al. 1996, Peacor and Werner 1997). Density-mediated indirect effects (DMIs) are transmitted by changes in the density of an intervening species (Abrams et al. 1996, Peacor and Werner 1997). For example, assume that increased abundance of species A has a direct negative effect on the abundance of species $\mathrm{B}$, and that increasing the abundance of species $\mathrm{B}$ has a direct and negative effect on the abundance of species C. Therefore, increased abundance of species A has an indirect positive effect on the abundance of species $\mathrm{C}$ through its interaction with species B. In contrast, trait-mediated indirect effects (TMIs) are changes in density of a species caused by induced changes in the trait(s) of an intervening species (e.g. behavior, morphology, life history; Abrams et al. 1996, Peacor and Werner 1997). In this case, increased abundance of species A directly affects a trait, not the abundance, of species B, which then has a direct effect on the abundance of species $\mathrm{C}$.

DMIs have received more theoretical and empirical attention, primarily because they are easier to detect (Wilbur and Fauth 1990, Schoener 1993, Menge 1995, 1997). Identifying DMIs requires pairwise comparisons of species abundances resulting from presence/absence experimental manipulations (Dungan 1986, Lively and Raimondi 1987, Wilbur and Fauth 1990). While TMIs can be detected by pairwise comparisons, characterizing them requires intricate knowledge of the system (i.e. the

Accepted 20 April 2000

Copyright C OIKOS 2000

ISSN 0030-1299

Printed in Ireland - all rights reserved 
particular behaviors, morphologies and/or life history traits of the species in the community). Therefore, the number of documented TMIs is relatively small and primarily includes behavioral traits (Huang and Sih 1990, Werner 1992, Abrams et al. 1996). Here we consider a class of traits that has received less attention, but which may be of great importance in determining community structure: environmentally induced polymorphisms. Specifically, we examine the effect of TMIs via a predator-induced polymorphism on an intertidal community.

\section{The community}

The mid-intertidal community in the northern Gulf of California is relatively simple and consists of four main sessile species: Chthamalus anisopoma, a small acorn barnacle ( $<8 \mathrm{~mm}$ basal diameter); the mussel Brachidontes semilaevis ( $<1 \mathrm{~cm}$ length); a brown encrusting alga, Ralfsia sp.; and the ephemeral green alga, Ulva sp. Mobile species include two important limpet grazers, Collisella strongiana and Collisella acutapex (both less than one cm total length) and two predatory whelks,
Acanthina angelica and Morula ferruginosa. At sites used in this investigation, Chthamalus dominates rock surfaces (Fig. 1), typically covering $50-80 \%$ of available substrate (see Raimondi 1990 for a detailed description of Clydes sites and dynamics, and see Lively et al. 1993 for a description of Punta Pinta). Virtually all barnacle recruitment occurs between May and September (Raimondi 1990). Brachidontes and Ralfsia are less common, and Ulva occurs sporadically, never covering more than $5 \%$ of rock surfaces. Although limpets are important at other sites in the northern Gulf of California (Dungan 1986), at Clydes they are rare and unlikely to affect the community significantly.

\section{The effects of Acanthina on Chthamalus: predation and predator-induced polymorphisms}

Adult Chthamalus is the primary prey item of Acanthina, but Acanthina will consume Brachidontes when barnacles become very rare (Raimondi and Lohse unpubl.). Acanthina uses its labial spine to penetrate the opercular plates of barnacles, and then consumes the soft tissues within the shell (Yensen 1979). This method
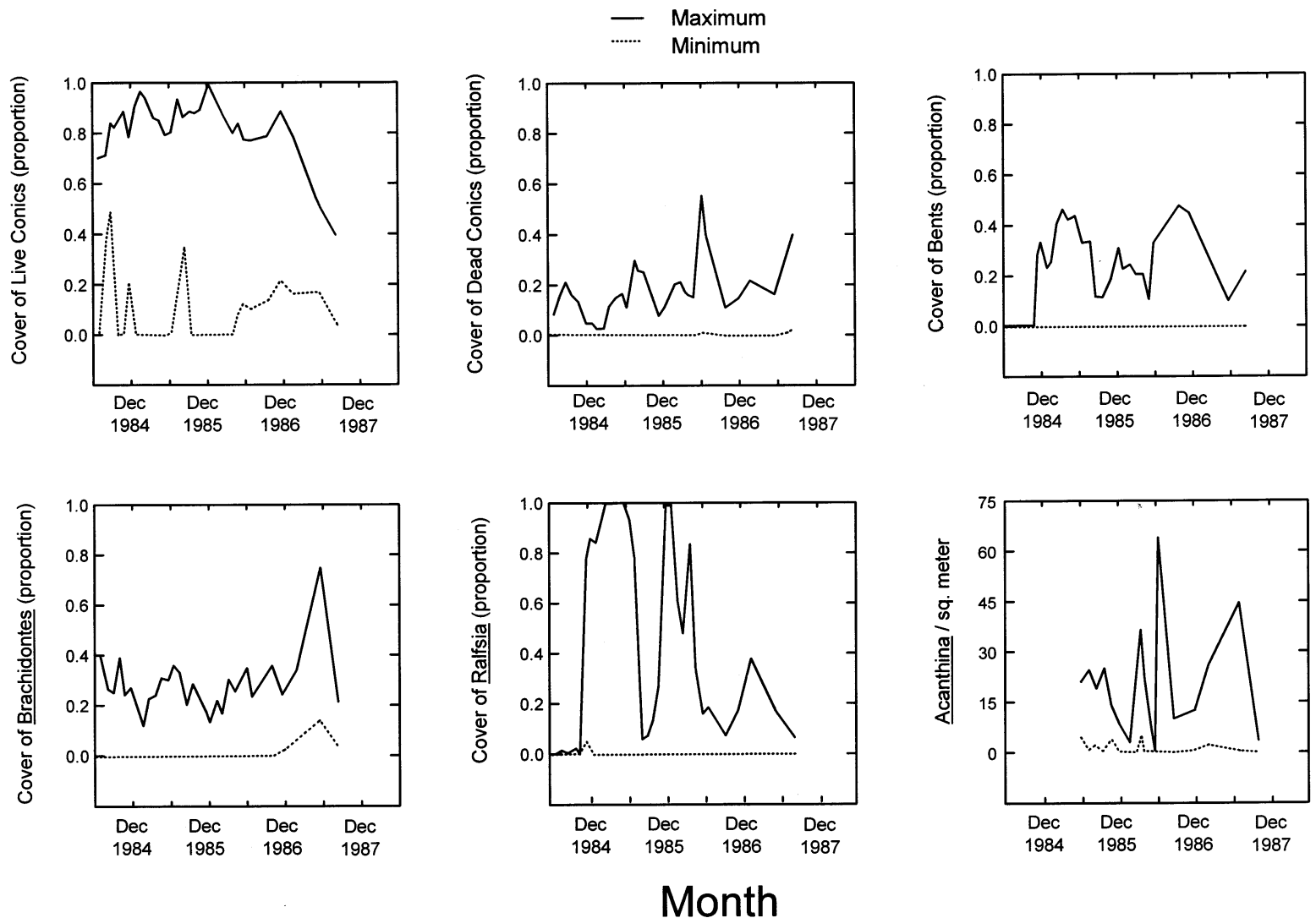

Fig. 1. Maximum and minimum values for cover of live conics, dead conics, bents, Brachidontes, Ralfsia and Acanthina during the sampling period. 
of predation significantly decreases the handling time required to consume a prey item compared to the alternative method of using a radular "drill" and leaves behind empty shells that are often colonized by mussels (Yensen 1979, Lively and Raimondi 1987).

Juvenile Chthamalus are generally not preyed upon by Acanthina (Lively 1986a, Lively et al. 2000). When Acanthina crawl over very young Chthamalus, a proportion $(20-40 \%)$ develops into a "bent" morph that is much more resistant to predation by Acanthina, but is less fecund and slower growing than the "conic" morph (Lively 1986b). Moreover, the probability that Chthamalus adopts the bent morphology is positively related to the number of contacts with Acanthina (Lively et al. 2000). Therefore, the population-level response depends on the time-lagged density of Acanthina. Vulnerability to predation is reduced in the bent morph because the opercular opening is turned $90^{\circ}$ from the typical upright position, which dramatically reduces penetration by the spine of Acanthina (Lively 1986a). This type of plasticity has been termed a developmental conversion, which is defined as an irreversible conversion of morphology in response to an environmental cue (Smith-Gill 1983, Lively 1986c).

While the bent morph is much more resistant to predation from Acanthina, there are also two direct costs to the defended morph: the bent morph is less fecund and grows about 10\% more slowly than conics after maturation (Lively 1986b). For all other measured life history or demographic parameters there was no difference between morphs. These included nonAcanthina induced mortality, desiccation resistance, intraspecific competitive ability, investment to shell and onset of reproduction (Lively 1986b).

Both shell morphs coexist in the intertidal, but the bent form is less common than the conic form for three reasons. First, the conic form is the "default" morphology that all individuals develop in the absence of cues from Acanthina within a few weeks of settlement (Lively et al. 2000). Second, predation by Acanthina is temporally and spatially heterogeneous, and whelks appeared to be less active in Summer, which corresponds with a peak in recruitment of Chthamalus (Dungan 1986, Lively 1986a, Raimondi 1990). Third, as noted above, only a proportion of Chthamalus receiving a cue from Acanthina will bend. In summary, Acanthina has two effects on barnacles: death, which produces empty conic tests due to direct predation on adults ("deads") or, a second, discrete morph ("bent") that develops in response to cues from Acanthina. The polymorphism meets the necessary conditions for an evolutionarily stable strategy, when modeled as a function of spatial and temporal variation in the environmental cue, coupled with the intrinsic fitness costs associated with the bent morphology (Lively 1986b, 1999).

\section{The effect of barnacles on mussel recruitment}

The mid-intertidal mussel population (Brachidontes semilaevis) in the Gulf of California differs from the well-studied Mytilus populations of the temperate regions of the Pacific and Atlantic coasts. Brachidontes are small, sometimes uncommon, and are distributed throughout the barnacle zone (Lively and Raimondi 1987). Previous work demonstrated that the typical (conic) morph of Chthamalus enhances mussel recruitment (Dungan 1986, Lively and Raimondi 1987). In experimental manipulations, Lively and Raimondi (1987) compared mussel recruitment in: (1) patches cleared of barnacles, (2) control patches (ambient proportions of living and dead barnacles) and (3) patches of dead barnacles killed by experimental spining, which mimicked predation by Acanthina. Mussels recruited only between the tests of living or dead barnacles or into the empty tests of dead barnacles. The effect of the bent morph on mussel abundance was not directly explored, because bents are not spined by Acanthina and empty tests of bents are extremely uncommon.

\section{Evidence for trait-mediated indirect effects}

The patterns described above led us to test for TMIs in this community. We predicted that two general hierarchies of interactions occur among the species in this assemblage, which produce different communities through different effects of Acanthina on Chthamalus (Fig. 2).

1) When Acanthina encounter patches of primarily adult barnacles, predation will occur, producing dead conics. The resultant mixture of dead and live conics will enhance recruitment of mussels. As a consequence, this should lead to reduced cover of Ralfsia through preemption of space by mussels.

2) In contrast, when Acanthina encounter patches consisting mainly of new barnacle recruits, a mixture of conics and bents will result. There is generally greater spacing between bents compared to between conics (Raimondi, pers. obs.), and the other typical settlement spot for mussels is in the "crevice" between two abutting conic barnacles. Such spots are uncommon in patches dominated by bents. Therefore, mussel abundance will be low. Ralfsia abundance should increase due to decreased competition for space with mussels.

We used the general predictions of community structure to create two specific predictions about the relationship among species: A) Increasing cover of live or dead conics leads to an increase in the cover of mussels and a decrease in cover of Ralfsia. B) Increasing cover of bents leads to a decrease in the cover of mussels and an increase in the cover of Ralfsia. Although percent cover 
A.

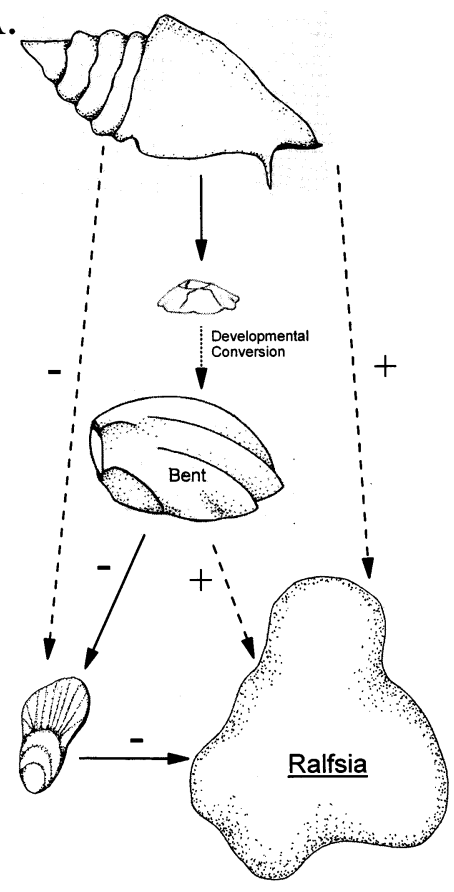

cannot increase indefinitely, the relationships should hold as long as mussel recruitment is not extremely high.

\section{Experimental design and analysis}

We used two approaches to test the hypothesized TMI. We first reevaluated the results of experimental removals of Acanthina done originally to determine why the number of bents is greatest near crevices that serve as refuges for Acanthina. While results of this experiment have been reported elsewhere (see Lively 1986a and Lively et al. 1993), that work examined the population-level effects of predator removal. We used data from this experiment to directly assess the hypothesis that foraging by Acanthina can lead to two different communities.

In January 1980, eight granite benches were selected at Punta Pinta, at tidal heights varying between +1 and $+2 \mathrm{~m}$ above MLW (mean low water). On each bench $\left(\sim 1 \mathrm{~m}^{2}\right.$ in area), two $15 \times 15-\mathrm{cm}$ plots were established near crevices (within $20 \mathrm{~cm}$ ) for a total of 16 plots. Acanthina used crevices as refuges and areas near crevices were much more prone to predation by Acanthina (Lively 1986a). All plots were cleared of attached species then "sterilized" using a propane torch. Fences were erected around one plot on each bench to exclude Acanthina (see Lively 1986a for details) and were maintained for 12 months at which point the fences were removed; the other plot was left as a control. Ten by ten-cm areas within the center of each plot were sampled once every one or two months for $5 \mathrm{yr}$ (and less often after $5 \mathrm{yr}$ - data not shown here). Percent cover of sessile species (live conics, dead conics, bents, Brachidontes and Ralfsia) and free space was measured using a clear, Plexiglas plate with 100 randomly placed dots (different dots each sample).

We predicted that the community was organized, in part, by the timing of interactions between Acanthina and Chthamalus. In our second approach, we manipulated a series of replicate plots to produce initially different cohorts of barnacles (from just settled to adult). Plots were located such that treatments (see below) were completely intermixed and therefore similar with respect to distance to whelk refuge and substrate relief and aspect. Hence, all plots should have experienced similar levels of foraging activity by Acanthina. In July 1984, four $10 \times 10$-cm plots were permanently marked at each of four rock benches. Treatments consisted of clearing and sterilizing the plots plus controls (not cleared or sterilized; two each per bench). Additional plots were cleared in October 1984 (two plots per bench), January 1985 (two plots per bench), April 1985 (two plots per bench), July 1985 (one plot per bench), and October 1985 (one plot per bench) to produce variation in recruitment and to provide inter-plot variation in the proportions of the three types of barnacle morphs: live conic, dead conic and bents (Fig. 1). Clearings made in Fall and Winter are more likely to have a high proportion of bents because Acanthina is more active in these seasons, and therefore whelks are more likely to come into contact with juvenile barnacles. Clearings made in the Spring 
and Summer are likely to have a high proportion of conics because Acanthina aestivates during this time period, and therefore is less likely to come into contact with juveniles (Lively 1999).

Percent cover of sessile species and free space were measured on a monthly basis through August 1986, and then periodically through February 1988. To test our specific predictions, percent cover data were analyzed using multivariate linear regressions. In all cases, percent cover was arcsine square root transformed prior to analysis to normalize the distributions (first tested for normality using probability plots, Zar 1984). We estimated the partial regression coefficients for all putative independent variables, which represent the slope of the best fit surface along the $X_{i}$ axis. Partial regression coefficients represent the regression of $Y$ on an independent variable when all other independent variables are held constant (Winer et al. 1991). This allowed exami-

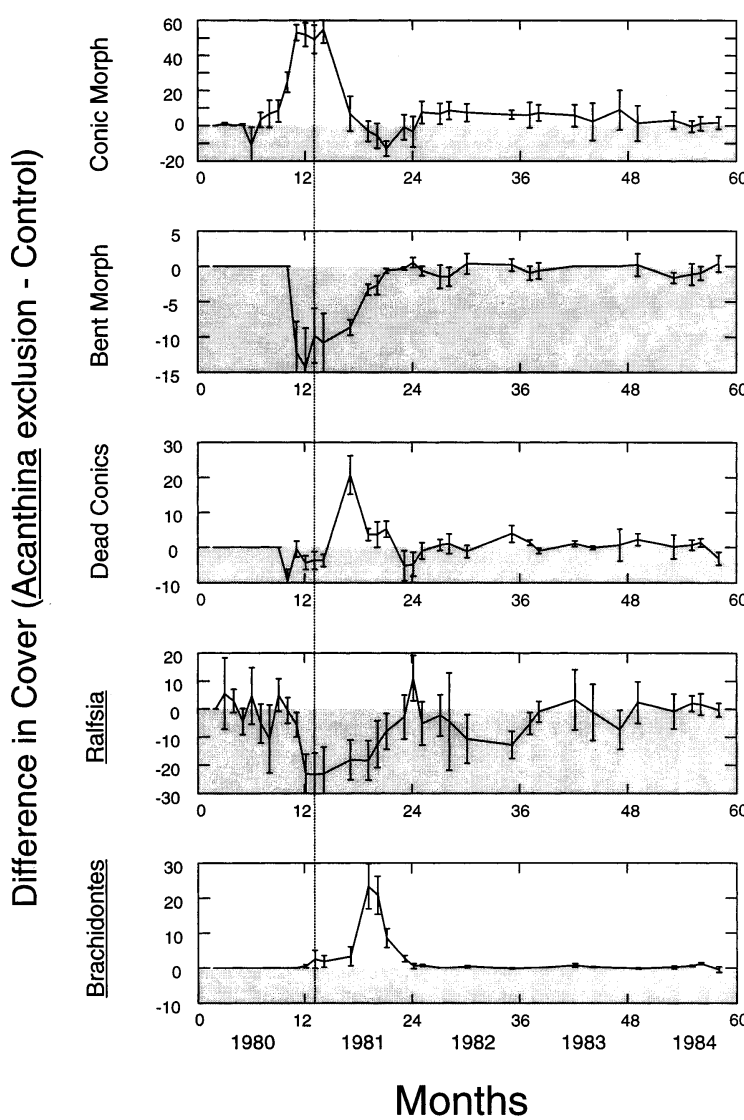

Fig. 3. Difference in cover of live conics, bents, dead conics, Ralfsia and mussels for Acanthina exclusion (-Acanthina) and control $(+$ Acanthina $)$ plots. Data plotted are the mean $( \pm 1$ se) differences between - Acanthina and + Acanthina plots on a bench (difference between pairs of plots on a bench). Dotted line indicates date when cages were removed from - Acanthina plots. Gray area indicates region where + Acanthina plots have higher cover than - Acanthina plots. White regions indicate regions where - Acanthina plots have higher cover than + Acanthina plots. nation of the direction and magnitude of effects by a suite of independent variables acting simultaneously on a dependent variable.

Three factors could affect our interpretation of the results. First, differences in density among live conics, dead conics and bents could confound interpretation of the effect of barnacle morphology on Brachidontes and Ralfsia. Although the ranges for percent cover of bents and dead conics were similar, both were often lower than live conics (Fig. 1). To address this issue, we parsed the data set to exclude any samples where the percent cover of live conics was greater than $50 \%$. This resulted in similar ranges of cover for all morphs: $0-50 \%$ for live conics, $0-56 \%$ for dead conics and $0-49 \%$ for bents.

Second, because data were collected from the same plots over time (usually monthly) temporal replicates could be autocorrelated. We addressed this problem by sampling a different set of random points each sample period and by only including samples separated by four-month intervals. Autocorrelation was examined using a Durbin-Watson test.

Third, our data were percent cover and clearly there could be an issue of independence given that by definition cover must sum to $100 \%$. However, our analyses included only four of seven measured variables and as a result there was no violation of the assumption of independence (sum of cover for analyses with Brachidontes as dependent variable: mean $=53 \%$; with Ralfsia as dependent variable: mean $=51 \%$ ).

\section{Results}

Results of experimental manipulations of Acanthina foraging supported the specific predictions (see above) and are presented in Fig. 3. At the time cages were removed (Acanthina re-invasion), the two treatments had different communities. Plots from which Acanthina were excluded ( - Acanthina plots) had far more conic individuals and fewer bents and Ralfsia than did control plots ( + Acanthina plots); cover of dead conics and mussels was similar between treatments. After cage removal, the cover of dead conics quickly increased in - Acanthina plots, followed by an increase in cover by mussels. - Acanthina and + Acanthina plots converged in the cover of bents and live and dead conics by about month 22 ( $\sim 10$ months after cages were removed), and as predicted, so did cover of mussels and Ralfsia (by about month 24).

Results of the second experiment also supported the specific predictions outlined above (Table 1). In the regression analysis, mussel cover was positively correlated with the cover of live and dead conics and negatively correlated with cover of bents. These results were similar to those of earlier experiments (Lively and 
Table 1. Comparison of specific predictions and results of analyses for the relationship between different morphologies of Chthamalus on Brachidontes and Ralfsia cover at Clydes site. Analyses performed on parsed data (to equalize density ranges for barnacle forms) that were arcsine (square root) transformed. Note all predictions were met (compare sign of coefficient to prediction) and that tests of autocorrelation were non-significant. $P$-values: ${ }^{\mathrm{a}}<0.001,{ }^{\mathrm{b}} 0.005,{ }^{\mathrm{c}}<0.01,{ }^{\mathrm{d}}<0.05$.

Results of multiple regressions on the percent cover of Brachidontes.

\begin{tabular}{lllr}
\hline Effect of increasing cover of & Prediction & Coefficient $(95 \%$ confidence interval) & $t$ \\
\hline Live conics & Positive correlation & $+0.560(0.456-0.564)$ & $10.60^{\mathrm{a}}$ \\
Dead conics & Positive correlation & $+0.313(0.164-0.462)$ & $4.13^{\mathrm{a}}$ \\
Bents & Negative correlation & $-0.411(-0.541-0.279)$ & $-6.13^{\mathrm{a}}$ \\
Constant & NA & $+0.067(0.014-0.119)$ & $2.49^{\mathrm{d}}$ \\
\hline
\end{tabular}

Durbin-Watson $D$ (test of autocorrelation) $=1.82, P \gg 0.05$.

Results of multiple regressions on the percent cover of Ralfsia.

\begin{tabular}{lllr}
\hline Effect of increasing cover of & Prediction & Coefficient $(95 \%$ confidence interval) & $t$ \\
\hline Live conics & Negative correlation & $-0.255(-0.433--0.077)$ & $-2.82^{\mathrm{b}}$ \\
Dead conics & Negative correlation & $-0.713(-0.968-0.459)$ & $-5.51^{\mathrm{a}}$ \\
Bents & Positive correlation & $+0.399(0.173-0.625)$ & $3.48^{\mathrm{a}}$ \\
Constant & NA & $+0.463(0.373-0.553)$ & $10.14^{\mathrm{a}}$ \\
\hline
\end{tabular}

Durbin-Watson $D$ (test of autocorrelation) $=1.95 ; P \gg 0.05$.

Raimondi 1987). As predicted, Ralfsia cover was negatively correlated with the cover of live and dead conics and positively correlated with cover of bents (Table 1). The negative effect due to live and dead conics is consistent with Dungan's (1986) conclusion that the direct negative effect of Chthamalus on Ralfsia is due to preemption of space.

\section{Discussion}

The results supported our predictions that two interaction hierarchies resulted from the differing effects of Acanthina on morphological traits of Chthamalus. Our results demonstrate that the indirect effects of Acanthina on Brachidontes and Ralfsia differed dramatically as a result of the predator-induced developmental conversion of Chthamalus (Fig. 2). Each interaction hierarchy comprised of predator-mediated direct effects on morphology (of Chthamalus), and density- (of different barnacle morphs) mediated direct effects on abundance of mussels or Ralfsia. The presence of alternative interaction hierarchies provided evidence for a trait-mediated indirect effect. Further, our results demonstrate community-wide effects of the predator of barnacles in this system. Predatory activity occurring within a few weeks of Chthamalus settlement led to communities with increased cover of bent morphs and Ralfsia and decreased cover of Brachidontes and both live and dead conic morphs. The critical feature driving this community was the bent morphology of Chthamalus. Conics were relatively uncommon because of the induction of the bent morph. Since Acanthina prey on conics, deads also were uncommon. Brachidontes were rare for two reasons: (1) the shape of the bent form left few suitable attachment sites and, (2) Acanthina consumed mussels when conics became rare. Finally, Ralfsia was relatively common due to release from competition for space with live and dead conics and mussels. By contrast, predatory activity occurring during later stages of Chthamalus development resulted in communities with decreased cover of bent morphs and Ralfsia and increased cover of Brachidontes and live and dead conic morphs. Again, the critical feature was the morphology of Chthamalus - here conic because predatory activity occurred after the critical induction period. Dead barnacles increased via direct predation on conics. Mussels also increased because there were more suitable attachment sites and because conics were available for consumption by Acanthina. Ralfsia decreased through preemption of space by barnacles and mussels. These alternative communities shifted between states over time as a result of the patchy distribution of Acanthina. In addition, the per-capita risk of being eaten or being induced to bend increased with Acanthina abundance, thus the community-level effects depended on the density of foraging Acanthina. Hence, the effect on the community depended on both the density of Acanthina and the ontogenetic timing of encounters between whelks and barnacles.

As noted earlier, one factor that could affect our ability to identify the importance of TMIs in the community was the difference in average densities among the Chthamalus morphs. The challenge was to separate the roles of trait-mediated and density-mediated interactions. We addressed this problem by using multiple regression techniques where the partial regression coefficients represented the regression of the variable of interest (e.g. mussel cover) on an independent variable (e.g. cover of bents) when all other independent variables were held constant (Morin 1983, Winer et al. 1991). We also parsed the data to standardize the range in cover for all barnacle morphs. Given the use of these 
two approaches, we are confident that our results correctly identified the presence of trait-mediated interactions in the community.

We were also interested in estimating the importance of the trait-mediated interactions. Densities of two species, Ralfsia and Brachidontes, which were shown to be affected by the alternate effects of Acanthina on Chthamalus varied tremendously among our plots. At Clydes site, the ranges in values for Brachidontes and Ralfsia were $0-80 \%$ cover and $0-100 \%$ cover, respectively (Fig. 1). At Punta Pinta, the ranges were $0-70 \%$ and $0-100 \%$ (data not shown). It is unlikely that all of the variance in cover was explained by the TMI; other factors such as recruitment variation and predation must also have been important. To estimate the potential importance of the demonstrated TMI in this system we did a simple exercise. Linear models were constructed using the coefficients from the regression analyses shown in Table 1. We compared two hypothetical patches where the cover of live conics was $30 \%$ in both patches and the cover of dead conics and bents was either $30 \%$ or $0 \%$ ("high deads patch" $=30 \%$ dead conics and $0 \%$ bents, "high bents patch" $=0 \%$ dead conics and $30 \%$ bents). Hence, the overall cover of barnacles (live conic, dead conic and bents) was held at $60 \%$, which was the average value over the $4 \mathrm{yr}$ of sampling at Clydes site. This exercise assumed: (1) a high foraging rate by Acanthina, which led to either death of adult conic barnacles or to induction of the bent morph for individuals exposed to Acanthina as new settlers, and (2) that the timing of Acanthina foraging and Chthamalus settlement produced "pure" stands of either bents or dead conics (no mixtures of these morphs). The results of this exercise point to the importance of the TMI in producing variability in the structure of the community: (1) the predicted cover of mussels was $29 \%$ in the "high deads patch" and $2 \%$ in the "high bents patch", and (2) the predicted cover of Ralfsia was $1 \%$ in the "high deads patch" and $27 \%$ in the "high bents patch".

\section{Potential in other systems}

Questions remain about the general importance of TMIs to community structure (Case and Bender 1981, Wilbur and Fauth 1990, Werner 1992, Adler and Morris 1994, Billick and Case 1994, Peacor and Werner 1997, Sih et al. 1998). If TMIs are generally important, models of community organization that do not incorporate them will not be accurate and/or predictive. Therefore, assessing the potential importance of TMIs should influence how ecologists model communities (Peacor and Werner 1997).

As far as we know, ours is the first evidence for TMIs via an environmentally induced polymorphism. Most studies testing for the presence of TMIs have focused on behavioral traits (Werner 1992, Abrams et al. 1996). Theoretical arguments for the presence of TMIs are often based on foraging theory, and therefore have motivated research examining the effects of changes in predator-prey interactions as a result of foraging shifts or changes in prey behavior (Werner 1992, Abrams et al. 1996). Other work on TMIs includes examining effects on larval anuran metamorphosis and growth rate (e.g. Wilbur and Fauth 1990).

We believe there is great potential for the presence of TMIs in communities via environmentally induced polymorphisms. Examples of environmentally induced polymorphisms (which could be of the form of developmental conversions or phenotypic modulation; see

Table 2. Examples of environmentally induced polymorphisms in terrestrial, freshwater, and marine systems. The potential for trait-mediated indirect effects also exists in plant-herbivore communities as a function of predator-induced chemical defenses in plants (reviewed by Lloyd and Bawa 1984, Karban and Baldwin 1997).

\begin{tabular}{|c|c|c|c|}
\hline $\begin{array}{l}\text { Taxon displaying } \\
\text { polymorphism }\end{array}$ & $\begin{array}{l}\text { Interaction inducing } \\
\text { polymorphism }\end{array}$ & Induced morphology & Reference \\
\hline $\begin{array}{l}\text { Rotifers (Brachionus } \\
\text { calyciflonis, Keratella } \\
\text { slacki) }\end{array}$ & $\begin{array}{l}\text { copepod predation } \\
\text { (Asplanchna sp.) }\end{array}$ & anterior and posterior spines & $\begin{array}{l}\text { Gilbert } 1967, \text { Gilbert and } \\
\text { Stemberger } 1984\end{array}$ \\
\hline $\begin{array}{l}\text { Bryozoans (Membranipora } \\
\text { membranacea) }\end{array}$ & $\begin{array}{l}\text { 'nudibranch predation } \\
\text { (Doridella steinbergae, } \\
\text { Onchidoris muricata) }\end{array}$ & $\begin{array}{l}\text { spines on zooecium, frontal } \\
\text { membrane }\end{array}$ & $\begin{array}{l}\text { Yoshioka 1982, Harvell 1984, } \\
1992\end{array}$ \\
\hline Daphnia pulex & $\begin{array}{l}\text { predation by Chaoborus } \\
\text { crystallinus }\end{array}$ & Crest & $\begin{array}{l}\text { Krueger and Dodson 1981, } \\
\text { Havel and Dodson } 1987\end{array}$ \\
\hline $\begin{array}{l}\text { Protozoans (Onychodromus } \\
\text { quadricornitus) }\end{array}$ & intraspecific predation & cell shape and size & $\begin{array}{l}\text { Kuhlman and Heckman } \\
\text { 1985, Wicklow } 1988\end{array}$ \\
\hline Gastropods (Nucella spp.) & crab predation & shell thickness & $\begin{array}{l}\text { Appleton and Palmer 1988, } \\
\text { Palmer } 1990\end{array}$ \\
\hline Carp (Carassius carrassius) & pike predation & increased body depth & Brönmark and Miner 1992 \\
\hline Coral (Agaricia agaricites) & competition & sweeper tentacles & Chorensky 1983 \\
\hline $\begin{array}{l}\text { Spadefoot toad (Scaphiopus } \\
\text { multiplicatus) }\end{array}$ & prey availability & $\begin{array}{l}\text { orbitohyoideus muscle size, } \\
\text { intestinal length }\end{array}$ & Pfennig 1992 \\
\hline $\begin{array}{l}\text { Gray treefrog (Hyla } \\
\text { chrysoscelis })\end{array}$ & predation by Anax junius & tailfin size and color & $\begin{array}{l}\text { McCollum and VanBuskirk } \\
1996\end{array}$ \\
\hline
\end{tabular}


West-Eberhard 1989), can be found in freshwater, marine and terrestrial systems (Table 2). Little or no research has tested for TMIs as a result of polymorphisms, but we believe the potential for communitylevel effects of polymorphisms in many systems is high. For example, recent work demonstrated inducible defenses in the blue mussel, Mytilus edulis, including increased shell thickness and number of byssal threads (Leonard et al. 1999). Waterborne chemical cues from the predatory crab, Carcinus maenus, induced thicker shells in juvenile mussels. The whelk, Nucella lapillus, also preys on $M$. edulis, using a radular drill to pierce the mussel shell to access the soft tissues for consumption (Palmer 1984). C. maenus may have a TMI on Nucella via the change in mussel shell thickness. If the presence of crabs induces increased shell thickness in mussels, this should result in a negative, trait-mediated indirect effect on whelks (decreased predation efficiency). Further, one can imagine a cascade of effects on the entire community as a result of this TMI. Nucella may switch to consuming more barnacles (Murdoch 1969) as a result of the negative effect of increased mussel shell thickness on predation efficiency. Increased predation on barnacles might then affect the abundance of other space occupiers in the community.

Another class of environmentally induced polymorphisms are those produced in response to the physical environment. There are numerous examples of these (see West-Eberhard 1989), and the effects on communities via TMIs (if the physical environment is considered in the interaction hierarchy) may be even higher than for polymorphisms induced by biological interactions. Finally, non-induced polymorphisms also are likely to lead to TMIs. Consider a discrete fixed polymorphism, such as seen in populations of the side blotched lizard, Uta stansburiana, or the marine isopod Paracerceis sculpta (Shuster and Wade 1991, Sinervo and Lively 1996). If the frequencies of morphs vary over space or time, particularly as a result of spatially or temporally variable selection pressure, community structure could differ due to indirect effects mediated via ecological differences among morphs.

In summary, community-level effects of TMIs through environmentally induced polymorphisms are predicted for many systems (Table 2). As evidence for inducible defenses continues to grow (Leonard et al. 1999), we urge researchers to assess the influence these polymorphisms have on community dynamics, particularly if one of the goals of community ecology is to accurately assess and predict community structure.

Acknowledgements - We would like to thank Peter Abrams, Eric Danner, Dan Doak, John Fauth, Dave Lohse, Bruce Lyon, Marc Mangel, Bruce Menge, Craig Osenberg, Barry Sinervo and members of the Megalab for comments on the manuscript. This study was supported by an NSF-MBRS graduate traineeship to S. Forde and the following grants to P. Raimondi: UCMEXUS, UC Santa Cruz Faculty Research Grant, UC-Southern California Educational Initiative and
OCE95-29730, OCE-9633329 and OCE9614091 from the National Science Foundation (Biological Oceanography Program). This is contribution number 18 from PISCO, the Partnership for Interdisciplinary Studies of Coastal Oceans: A Long-Term Ecological Consortium funded by the David and Lucile Packard Foundation (P.R).

\section{References}

Abrams, P. A., Menge, B. A., Mittlebach, G. G. et al. 1996. The role of indirect effects in food webs. - In: Polis, G. A. and Winemiller, K. O. (eds), Food webs: integration of patterns and dynamics. Chapman and Hall, pp. 371-393.

Adler, F. R. and Morris, W. F. 1994. A general test for interaction modification. - Ecology 75: 1552-1559.

Appleton, R. D. and Palmer, A. R. 1988. Water-borne stimuli released by predatory crabs and damaged prey induce more predator-resistant shells in a marine gastropod. Proc. Natl. Acad. Sci. USA 85: 4387-4391.

Billick, I. and Case, T. J. 1994. Higher order interactions in ecological communities: what are they and how can they be detected? - Ecology 75: 1529-1543.

Brönmark, C. and Miner, J. G. 1992. Predator-induced phenotypical change in body morphology in crucian carp. Science 258: 1348-1350.

Case, T. J. and Bender, E. A. 1981. Testing for higher order interactions. - Am. Nat. 118: 920-929.

Chorensky, E. A. 1983. Induced development of sweeper tentacles of the reef coral Agaricia agaricites: a response to direct competition. - Biol. Bull. 165: 569-581.

Dungan, M. L. 1986. Three-way interactions: barnacles, limpets, and algae in a Sonoran Desert rocky intertidal zone. - Am. Nat. 127: 292-316.

Gilbert, J. J. 1967. Asplanchna and postero-lateral spine production in Brachionus calyciflorus. - Arch. Hydrobiol. 64: $1-62$.

Gilbert, J. J. and Stemberger, R. S. 1984. Asplanchna-induced polymorphism in the rotifer Keratella slacki. - Limnol. Oceanogr. 29: 1309-1326.

Harvell, C. D. 1984. Predator-induced defense in a marine bryozoan. - Science 224: 1357-1359.

Harvell, C. D. 1992. Inducible defenses and allocation shifts in a marine bryozoan. - Ecology 73: 1567-1576.

Havel, J. and Dodson, S. 1987. Reproductive costs of Chaoborus-induced polymorphism in Daphnia pulex. - Hydrobiologia 150: 273-281.

Huang, C. and Sih, A. 1990. Experimental studies on behaviorally mediated, indirect interactions through a shared predator. - Ecology 71: 1515-1522.

Karban, R. and Baldwin, I. 1997. Induced responses to herbivory. - Univ. of Chicago Press.

Kuhlman, H. W. and Heckman, K. 1985. Interspecific morphogens regulating predator-prey relationships in protozoa. - Science 227: 1347-1349.

Krueger, D. A. and Dodson, S. I. 1981. Embryological induction and predation ecology in Daphnia pulex. - Limnol. Oceanogr. 26: 219-223.

Leonard, G. H., Bertness, M. D. and Yund, P. O. 1999. Crab predation, waterborne cues, and inducible defenses in the blue mussel, Mytilus edulis. - Ecology 80: 1-14.

Lively, C. M. 1986a. Predator-induced shell dimorphism in the acorn barnacle Chthamalus ansipoma. - Evolution 40: $232-242$.

Lively, C. M. 1986b. Competition, comparative life histories, and maintenance of shell dimorphism in a barnacle. Ecology 67: 858-864.

Lively, C. M. 1986c. Canalization versus developmental conversion in a spatially variable environment. - Am. Nat. 128: $561-572$.

Lively, C. M. 1999. Developmental strategies in spatially variable environments: barnacle shell dimorphism and 
strategic models of selection. - In: Tollrian, R. and Harvell C. D. (eds), The ecology and evolution of inducible defenses. Princeton Univ. Press, pp. 245-258.

Lively, C. M. and Raimondi, P. T. 1987. Desiccation, predation, and mussel-barnacle interactions in the northern Gulf of California. - Oecologia 74: 304-309.

Lively, C. M., Raimondi, P. T. and Delph, L. F. 1993. Intertidal community structure: space time interactions in the northern Gulf of California. - Ecology 74: 162-173.

Lively, C. M., Hazel, W. N., Schellenberger, M. and Michelson, K. S. 2000. Predator-induced defense: variation for inducibility in an intertidal barnacle. - Ecology 81: 1240-1247.

Lloyd, D. G. and Bawa, K. S. 1984. Modification of the gender of seed plants in varying conditions. - Evol. Biol. 17: 255-338.

McCollum, S. A. and VanBuskirk, J. 1996. Costs and benefits of a predator-induced polyphenism in the gray treefrog Hyla chrysoscelis. - Evolution 50: 583-593.

Menge, B. A. 1995. Indirect effects in marine rocky intertidal interactions webs: patterns and importance. - Ecol. Monogr. 65: 21-74.

Menge, B. A. 1997. Detection of direct vs. indirect effects: were experiments long enough? - Am. Nat. 149: 801-823.

Morin, P. J. 1983. Predation, competition, and the composition of larval anuran guilds. - Ecol. Monogr. 53: 119-138.

Murdoch, W. W. 1969. Switching in general predators: experiments on predator specificity and stability of prey populations. - Ecol. Monogr. 39: 335-354.

Palmer, A. R. 1984. Prey selection by thaidid gastropods: some observational and experimental field tests of foraging models. - Oecologia 62: 162-172.

Palmer, A. R. 1990. Effect of crab effluent and scent of damaged conspecifics on feeding, growth, and shell morphology of the Atlantic dogwhelk Nucella lapillus (L.). Hydrobiologia 193: 155-182.

Peacor, S. D. and Werner, E. E. 1997. Trait-mediated indirect interactions in a simple aquatic food web. - Ecology 78: 1146-1156.

Pfennig, D. W. 1992. Polyphenism in spadefoot toad tadpoles as a locally adjusted evolutionary stable strategy. - Evolution 46: $1408-1420$.
Raimondi, P. T. 1990. Patterns, mechanisms and consequences of variability in settlement and recruitment of an intertidal barnacle. - Ecol. Monogr. 60: 283-309.

Schoener, T. W. 1993. On the relative importance of indirect effects in ecological communities. - In: Kawanabi, H. Cohen, J. and Iwasaki, I. (eds), Mutualism and community organization. Oxford Univ. Press, pp. 365-411.

Shuster, S. M. and Wade, M. J. 1991. Equal mating success among male reproductive strategies in a marine isopod. Nature 350: 608-610.

Sih, A., Englund, G. and Wooster, D. 1998. Emergent impacts of multiple predators on prey. - Trends Ecol. Evol. 13: $350-355$

Sinervo, B. and Lively, C. M. 1996. The rock-paper-scissors game and the evolution of alternative male strategies. Nature 380: 240-243.

Smith-Gill, S. J. 1983. Developmental plasticity: developmental conversion vs. phenotypic modulation. - Am. Zool. 23: $47-55$.

Werner, E. E. 1992. Individual behavior and higher-order species interactions. - Am. Nat. 140: S5-S32.

West-Eberhard, M. J. 1989. Phenotypic plasticity and the origins of diversity. - Annu. Rev. Ecol. Syst. 20: 249-278.

Wicklow, B. J. 1988. Developmental polymorphism induced by intraspecific predation in the ciliated protozoan Onchyodromus quadricornutus. - J. Protozool. 35: 137-141.

Wilbur, H. M. and Fauth, J. E. 1990. Experimental aquatic food webs: interactions between two predators and two prey. - Am. Nat. 35: 176-204.

Winer, B. J., Brown, D. R. and Michels, K. M. 1991. Statistical principles in experimental design. - McGraw-Hill.

Yensen, N. P. 1979. The function of the labile spine and the effect of prey size on "switching" polymorphisms of Acanthina angelica (Gastropoda: Thaididae). - Ph.D. dissertation, Univ. of Arizona, Tucson, AZ.

Yoshioka, P. M. 1982. Predator-induced polymorphism in the bryozoan, Membranipora membranacea (L.). - J. Exp. Mar. Biol. Ecol. 61: 233-242.

Zar, J. H. 1984. Biostatistical analysis. - Prentice-Hall. 